Theoretical Linguistics 41(2015): 97-103.

\title{
Neutrality and variation: what are they?
}

\author{
Péter Siptár \\ Eötvös Loránd University Budapest and \\ Hungarian Academy of Sciences \\ siptar.peter@nytud.mta.hu
}

In this brief contribution, I will raise two basic issues - where basic is meant both as 'elementary' and as 'fundamental') that are at the heart of Rebrus and Törkenczy's (R\&T's) paper. Both of these issues involve notions that are somehow taken for granted by the authors and are not given much consideration. Very simply put, they can be summarised as follows:

(1) a. What makes an $\mathrm{N}$ an $\mathrm{N}$, and how can you recognise one when you see it?

b. Are 'lexical variation' and 'vacillation' the same thing or are they different?

With respect to the first problem, that of neutral vowels, the authors note in passing that the distinction between harmonic and neutral vowels is (normally) gradual, rather than categorical; but then they assume a "once an $\mathrm{N}$, always an $\mathrm{N}$ " stance (recall the old structuralist dictum "once a phoneme, always a phoneme") and capitalise on the intuitive notion of 'neutral vowel' which we all seem to share without looking more closely. In doing so, they abstract away from as much detail as possible. In particular, with respect to Hungarian, they deliberately ignore the Height Effect (Hayes and Cziráky Londe 2006) and Harmonic Uniformity (Rebrus and Törkenczy 2015); and, in general terms, they disregard the potentially non-uniform occurrence of individual neutral vowels in invariable suffixes or in anti-harmonic stems (in systems with more than one neutral vowel), as well as any other aspect that might make the system non-categorical, controversial, or messy (except for variation, broadly construed, that has a distinguished and eminent role in the analysis they present). With respect to the second problem, the authors simply subsume both phenomena concerned - quite distinct as they appear to be at first sight - under a common label, and do not discuss whether or not they are right in doing so in any detail (except for a brief mention, in footnote 39, of Hayes et al. (2009) who also refer to them by an umbrella term, 'zones of variation'). This is all the more important since their key explanatory device, monotonicity, actually hinges on whether or not 'variation' in R\&T's sense is a single coherent concept.

\section{Neutral vowels}

The authors offer three fundamental properties of neutral vowels that define them as such: neutral vowels (i) "may have the ability to co-occur with members of either harmonic class of vowels within the morpheme", (ii) [may] "occur in non-alternating (invariant) affixes that can combine with stems whose harmonic trigger vowels may be of either harmonic class", and (iii) "may co-occur with affixal vowels of either harmonic class" when they are the only type of vowel found in a stem. Given that all three properties are presented by R\&T as potentially - but not necessarily - involved whenever a vowel is to be classified as neutral, the question arises if all three criteria are indeed necessary in a given system or only two, or even only one of them is enough for a vowel or a set of vowels to qualify as neutral. And even in a system 
where all three properties are available (as in Hungarian): do they have to be simultaneously true of a particular (type of) vowel if it is to be called 'neutral'?

Property (iii) is clearly not mandatory (see e.g. (9a-b) in R\&T's paper), and is closely related to the issue of lexical variation, so I will return to it in section $\mathbf{2}$ below and will disregard it for the time being. On the other hand, a fourth property, transparency, is often claimed in the literature to define/characterise neutral vowels. Again, since R\&T take opacity to be a possible type of behaviour for neutral vowels (see (9a)), transparency is not taken to be a necessary precondition for neutral status, either. The issue of invariant suffixes (property (ii)) is by and large ignored throughout the paper; but we might rightly ask if, in a language that is like Eastern Khanty in (9a) but happens not to exhibit invariant suffixes at all, we would still classify some vowels as neutral or not. Indeed, given the possibility of what the authors refer to as 'strong disharmony', i.e., the possibility of BF and FB sequences occurring within morphemes even in a vowel harmony language, a system with opacity and no antiharmony or invariant affixes could clearly be characterised as one in which there is a (perhaps heavier than usual) incidence of strongly disharmonic morphemes, but no neutral vowels at all.

Furthermore, in a system like (9a), it is not only the case that invariant suffixes may be literally lacking. Even if there are invariant suffixes containing what appear to be neutral vowels, they are necessarily opaque (due to the fact that the system does not admit transparency in general), hence their vowels are not neutral in the relevant sense: such suffixes are not different from non-alternating but non-neutral ones like the Turkish progressive /-(i)jor/ or the Hungarian temporal/-kor/ (see footnote 7) - except that they are front-harmonic, rather than back-harmonic. Such a system would simply have strong disharmony not only within but also across morphemes, and the issue of neutral vowels would not arise.

On the other hand, a system with anti-opacity and anti-harmony (with or without invariant suffixes) like Eastern Vepsian (9d) may well be claimed to be one where the putative neutral vowels are simply classified as back vowels. One might object that neutral vowels are phonetically front, a fact that warrants their phonological classification as neutral if they co-occur with back vowels even if no other component of neutrality is present; yet it is not completely impossible (though, admittedly, unexpected and rare) for a vowel to be phonetically front and harmonically clearly back (not neutral). One such example is the case of /a:/ in Hungarian: this vowel is currently undergoing a shift in place of articulation from central to front, yet its position within the system of Hungarian vowel harmony as a 'back vowel' remains firm and undisturbed. For the details and some related discussion, see Gósy and Siptár (2015) and the literature cited there. (It is true that the two cases still differ in the fact that Hungarian /a:/ is not merely phonetically front but it also has a harmonically - as well as phonetically - front counterpart to alternate with, which is apparently not the case with the Eastern Vepsian 'neutral vowel'. Although this makes the parallel less than perfect, it makes the /a:/ case even more surprising.) In the Vepsian case, then, all 'neutral' vowels would be harmonically back (though superficially front); their co-occurrence with front vowels would constitute just another case of strong disharmony.

Another complicating factor concerning whether a vowel is or is not neutral in a given system arises with respect to the interaction of transparency and the distinction between alternating vs. non-alternating affixes. In Hungarian at least, vowels that are otherwise neutral (and transparent) may occur in alternating suffixes as their front alternant as in -nál/-nél 'adessive', -ság/-ség 'nominalising suffix', -ban/-ben 'inessive', -talan/-telen 'privative suffix', etc.; this also happens, even if rather exceptionally, to /i/, the prototypical neutral vowel of this language, as in -ja/-i '3sg definite' (e.g. lát-ja 'sees it' vs. néz-i 'watches it'). As soon as this happens, such vowels immediately start behaving as front-harmonic (non- 
neutral). Alternatively, we can say that they are still 'neutral vowels' but behave opaquely rather than transparently: as I suggested above, this practically amounts to their ceasing to be neutral. Whichever way we choose to see this, the fact is that any subsequent suffix will invariably be front rather than back (or again, opaque-neutral rather than transparent). For further discussion, see e.g. Törkenczy (2013). The upshot of all this is that the "once an N, always an N" view adopted by R\&T in this paper leads to massive oversimplification and buys relative simplicity at the rather high price of losing sight of a number of respects in which 'neutral vowel' itself is a variable, gradual, and context-dependent notion.

One final point concerning neutral vowels, and one that takes us to the issue of variation discussed in the next section, is this: in and around footnote 47, the authors observe that although the literature usually claims that variation is typical in a [BNN] context, they found front-vowel affixation in only $8 \%$ of the cases, that is, a strong preference for back harmony. But then, this is mainly due to the fact that they restricted their calculation of "frontness ratios" to monosyllabic harmonizing inflectional suffixes (excluding all derivational suffixes, all invariant suffixes, and all suffixes or suffix combinations that are longer than a single syllable), and to stems that are exactly trisyllabic (in this case), are monomorphemic, and contain /i/ or /i:/ in both $\mathrm{N}$ positions, to the exclusion of /e:/ and / $/ \varepsilon /$ and any combination thereof. Since the variation in [BNN] contexts that the literature is so keen on discussing (see section 2 immediately below) is mainly due to the aspects that the authors abstract away from (or simply ignore), no wonder they find a relatively low rate of variability here.

\section{Variation}

The most important key notion of the second half of the paper, 'variation', is used by R\&T with systematic ambiguity. The two senses they attribute to this term are what they call 'lexical variation' between items like hiv(-ok) '(I) invite' and hiv(-ek) 'churchgoer(s)' and 'vacillation', i.e., inter-speaker and/or intra-speaker variability, in the behaviour of items like affér-ban $\sim$ affér-ben 'in a quarrel' or horribilis-an horribilis-en 'horribly (e.g. expensive)'. In principle, these two uses of the term 'variation' relate to one another like the classical notions of complementary distribution and free variation do. Of the monosyllabic free forms containing /i/ or /i:/, according to the very conservative calculation of the authors, over onequarter are back-harmonic ('anti-harmonic'); of the monosyllabic verbs containing one of those vowels, over three-quarters are. And if we also count the numerous bound stems, nominal and verbal ones alike, that ratio may well go even higher. An overwhelming majority of all-neutral stems exhibit clear-cut complementary distribution in their harmonic behaviour (with the monosyllabic /i(:)/-stems, this is $100 \%$ true). Some researchers claim that this complementarity even extends to the actual phonetic realisations of these items, even when pronounced in isolation (Benus and Gafos 2007). In other words, the /i(:)/ in these items is claimed to be articulated (and sound) slightly differently depending on whether they are antiharmonic or otherwise. Whether or not this is actually true (cf. Blaho and Szeredi 2013), the fact remains that there is absolutely no vacillation in these items as far as their harmonic behaviour is concerned.

On the other hand, the harmonic behaviour of many [BNN] and [BN] stems vacillates (Siptár and Törkenczy 2000). For instance, analizis-sel/-sal 'with analysis', matiné-re/-ra 'to a morning performance', protézis-ek/-ok 'dentures'; dzsungel-ben/-ban 'in the jungle', konkrét-en/-an 'concretely', and so on. In these cases, the same lexical item behaves in two different manners in what is essentially 'free variation'. Several familiar factors (and also some unknown ones) affect the exact proportions of occurrence of the competing forms, including the Count Effect and the Height Effect, as well as Harmonic Uniformity, but lexical 
variation (here meaning lexeme-specific, lexically determined differences in percentages) does not appear to have a say in this matter.

If this were the whole story, we could conclude that lumping these two totally dissimilar and distinct cases together and taking them to constitute a single coherent phenomenon called 'variation' is a serious flaw in R\&T's analysis. Fortunately, matters are somewhat more complicated. To start with variation in transparency, it certainly has its lexically determined aspects, too. For instance, although practically all $\mathrm{Bi}(:)$ stems behave transparently (no vacillation), some rare cases of vacillation can nevertheless be found (e.g. Aliz-nek/-nak 'Alice-dative'). Conversely, a tiny minority of $\mathrm{B} \varepsilon$ stems are transparent (haver-nak 'paldative'), a larger but still small set is opaque (kódex-ben 'in a codex'), whereas the majority of such items vacillate (hotel-ben/-ban 'in a hotel'). (Beq stems exhibit neither vacillation nor lexical variation: all of them behave opaquely: operett-ek 'operettas', november-ben 'in November'.) In between these two extremes, Be: stems are mainly transparent (kávé-nak 'coffee-dative', tányér-nak 'plate-dative', rostély-nak 'grid-dative') but some of them do vacillate. Among the vacillating items, the actual proportions of occurrence differ widely, also on a lexical basis. The following table, containing Google hits from 2007, comes from Hayes et al. (2009: 830):

$\begin{array}{llrr}\text { (2) domén-nak } & \text { '(net) domain-dative' } & 5 & 2.1 \% \\ \text { domén-nek } & & 234 & 97.9 \% \\ \text { bohém-nak } & \text { 'easy-going-dative' } & 433 & 24.4 \% \\ \text { bohém-nek } & & 1,340 & 75.6 \% \\ \text { honvéd-nak } & \text { 'Hungarian soldier-dative' } & 8,820 & 74.1 \% \\ \text { honvéd-nek } & & 3,084 & 25.9 \% \\ \text { poén-nak } & \text { 'punch line-dative' } & 56,400 & 99.9 \% \\ \text { poén-nek } & & 36 & 0.1 \%\end{array}$

In sum, the vacillating/non-vacillating distinction, as well as the actual proportions of occurrence within the vacillating camp, are lexically determined; hence, 'lexical variation' is heavily involved in vacillation, too. On the other hand, anti-harmony also involves some vacillation at the fringes along with an overwhelming share of categorical distinctions. As R\&T also point out in footnote 28, the items férfi 'man' and derék 'waist', in addition to being exceptions/counterexamples to their Polysyllabic Split (férfi-ak 'men', férfi-as 'masculine'; derék-on 'on waist', derek-am 'my waist), also exhibit some variation in other inflected forms (primarily with case markers): férfi-nak/-nek 'man-dative', derék-ban/-ben 'in waist'. In addition, izé 'thingummy' exhibits inter-speaker variability, with most Hungarian speakers preferring izé-vel 'with thingummy' categorically, whereas others allowing, or even preferring, izé-val.

All in all, the facts of lexical variation and vacillation are rather inextricably interconnected in this language. Hence, although in principle their identification as one and the same thing is still problematic, I cannot, after all, blame the authors for treating them as a single class.

\section{Conclusion}

In this commentary, I have raised two issues that are potentially problematic for Rebrus and Törkenczy's analysis of the typology of front/back harmony. With respect to the first, the issue of neutrality, I concluded that although it is somewhat poorly defined and loosely applied by R\&T, for the purposes of this paper its use is, on the whole, more or less well- 
taken. As concerns the second issue, with some theoretical reservations maintained, the combined treatment of the two types of variation cannot be seriously objected to on the practical level.

\section{References}

Benus, Stefan \& Adamantios I. Gafos 2007. Articulatory characteristics of Hungarian 'transparent' vowels. Journal of Phonetics 35: 271-300.

Blaho, Sylvia \& Dániel Szeredi 2013. Hungarian neutral vowels: A microcomparison. Nordlyd 40: 20-40.

Gósy, Mária \& Péter Siptár 2015. Abstractness or complexity? In: K. É. Kiss, B. Surányi \& É. Dékány (eds.), Approaches to Hungarian: Volume 14: Papers from the 2013 Piliscsaba Conference. Amsterdam \& Philadelphia: John Benjamins, 147-165.

Hayes, Bruce \& Zsuzsa Cziráky Londe 2006. Stochastic phonological knowledge: The case of Hungarian vowel harmony. Phonology 23: 59-104.

Hayes, Bruce, Kie Zuraw, Péter Siptár, \& Zsuzsa Londe 2009. Natural and unnatural constraints in Hungarian vowel harmony. Language 85: 822-863.

Rebrus, Péter \& Miklós Törkenczy 2015. Variation and subpatterns of disharmony in Hungarian. Poster presented at the 12th Old World Conference in Phonology (OCP 12), Barcelona, 27-30 January.

Siptár, Péter \& Miklós Törkenczy 2000. The phonology of Hungarian. Oxford: Oxford University Press.

Törkenczy, Miklós 2013. The close-ups can get rough: exceptional behaviour, transparency and variation in Hungarian vowel harmony. Paper presented at the 21th Manchester Phonology Meeting, Manchester, 23-25 May. 